\title{
Modifications to the representation of subgrid mixing in kilometre-scale versions of the Unified Model
}

Article

Accepted Version

Hanley, K., Whitall, M., Stirling, A. and Clark, P. (2019) Modifications to the representation of subgrid mixing in kilometre-scale versions of the Unified Model. Quarterly Journal of the Royal Meteorological Society, 145 (725). pp. 3361-3375. ISSN 1477-870X doi:

https://doi.org/10.1002/qj.3624 Available at https://centaur.reading.ac.uk/85355/

It is advisable to refer to the publisher's version if you intend to cite from the work. See Guidance on citing.

To link to this article DOI: http://dx.doi.org/10.1002/qj.3624

Publisher: Wiley

All outputs in CentAUR are protected by Intellectual Property Rights law, including copyright law. Copyright and IPR is retained by the creators or other copyright holders. Terms and conditions for use of this material are defined in the End User Agreement. 


\section{CentAUR}

Central Archive at the University of Reading

Reading's research outputs online 


\section{Modifications to the representation of subgrid}

\section{mixing in kilometre-scale versions of the Unified}

\section{Model}

\section{irsty Hanley $^{1 *} \quad$ | Michael Whitall ${ }^{2}$ | Alison Stirling ${ }^{2}$}

\section{Peter Clark ${ }^{3}$}

letOffice@Reading, University of

ading, Reading, UK

2. let Office, Exeter, UK

${ }^{3}$ Dept. of Meteorology, University of

Reading, Reading, UK

Correspondence

sty Hanley, MetOffice@Reading,

University of Reading, Reading, UK

ail: kirsty.hanley@metoffice.gov.uk

A mixed subgrid scheme for scalars and momentum fluxes in cloud-resolving models which includes an extra subgrid vertical flux, referred to as "the Leonard term", that accounts for the tilting of horizontal flux into the vertical by horizontal gradients in vertical velocity was proposed by Moeng. Here we describe the implementation of the Leonard term in the current subgrid mixing scheme used in kilometre-scale versions of the Met Office's Unified Model. We present results that show that including this extra term in the Met Office's $1.5 \mathrm{~km}$ grid length UK model reduces the domain-average precipitation by reducing the number of grid points with rainfall rates greater than $4 \mathrm{~mm} \mathrm{hr}^{-1}$, which are over-represented by the model. Increasing the magnitude of the Leonard terms further decreases the occurrence of the heaviest rainfall rates.

\section{KEYWORDS}

convection, subgrid mixing, Leonard term, tilting,

convection-permitting-models

This article has been accepted for publication and undergone full peer review but has not been through the copyediting, typesetting, pagination and proofreading process, which may lead to differences between this version and the Version of Record. Please cite this article as doi: 10.1002/qj.3624 


\section{INTRODUCTION}

Convective storms, and their associated hazards (flash floods, hail, lightning and severe winds), present an important farecasting problem in the UK. Such events can have wide-ranging impacts on livelihoods and infrastructure, so the timing and location of convective storms, as well as their evolution, are important to forecast accurately. The introductign of kilometre-scale numerical weather prediction (NWP) models for limited-area, short-range weather forecasting by many operational forecast centres, including the Met Office, has provided a step-change in predicting convection lark et al., 2016). In these models convection is represented explicitly rather than by a convection parameterisation. A number of studies (Lean et al., 2008; Kain et al., 2008; Weisman et al., 2008; Schwartz et al., 2009; Kendon et al., (1) 2 12; Nguyen et al., 2017) have shown that kilometre-scale models currently yield qualitatively more realistic precipitation fields and are quantitatively more skilful than lower resolution simulations with current convection parameteration schemes. However, a grid length of order $1 \mathrm{~km}$ is still not sufficient to fully resolve the individual convective 1 rements (e.g. Bryan et al., 2003) leading to convection still being under resolved (hence such models are referred to as "convection-permitting" rather than "convection-resolving"). This leads to significant shortcomings in the nature of the convective clouds simulated at these resolutions. For example, convective initiation in the Met Office's current $1.5 \mathrm{~km}$ id length UK model tends to lag observations and the convective cells tend to be too large and too circular, with too uch heavy rain and not enough light rain (e.g. McBeath et al., 2013; Hanley et al., 2015; Stein et al., 2015), illustrating our lack of understanding of the nature of small-scale mixing and microphysical processes. 
A fundamental problem with kilometre-scale models is that the storms are under-resolved. Although not yet feaMe operationally, one approach is to run models at higher resolution. At the Met Office, models with grid lengths a wn to $100 \mathrm{~m}$ have been run for UK and US convection. The benefits of this for convection include improvements in the onset time of precipitation, a more realistic distribution of rainfall rates and better organisation of individual Gonvective cells into larger complexes such as supercells (Hanley et al., 2015; Hanley et al., 2016). Another approach is to implement a grey-zone convection scheme. Currently at the Met Office a number of major changes to the Unified Model (UM) convection parameterisation are being developed, that will allow it to be implemented at convection permitting resolutions. The current UM convection scheme (as implemented in the Global Atmosphere version 6.1 scice configuration: Walters et al., 2017) is not appropriate for representing the smaller, unresolved updrafts in these models because it is designed to represent an equilibrium state including the whole spectrum of cumulus updrafts. Si ce that includes the deep convective storms which are resolvable by convection-permitting models, it degrades the performance if used in convection-permitting models. To address these issues the new convection scheme will be both ale-aware and stochastic. A third approach, which will be adopted here, is to improve the representation of subgrid 1 . mixing in convection-permitting models.

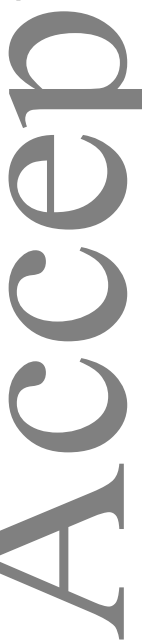


Moeng et al. (2010) propose an extension to the Smagorinsky-Lilly subgrid turbulence scheme, adding a contribution to turbulent fluxes from near-grid-scale unresolved fluxes related to horizontal gradients in vertical velocity and the transported scalars; the so-called Leonard term fluxes. It is shown in this paper (Sec. 2) that terms with very similar rm arise by including the tilting of fluxes that is generally neglected from turbulent flux budgets. This term clearly could be important in regimes where horizontal gradients become important, i.e. in convection permitting models, but t) impact needs to be assessed in real cases.

A recent study by Verrelle et al. (2017) implemented the Leonard term fluxes in the Meso-NH model at grid lengths 10

0) 2, 1 and $0.5 \mathrm{~km}$. They refer to this as an $\mathrm{H}$-gradient approach as it uses horizontal gradients as opposed to the traditional $K$-gradient approach used in conventional subgrid mixing schemes (i.e. Smagorinsky-Lilly or TKE schemes). THey only applied the Leonard term to vertical thermodynamic fluxes above the PBL (assuming a height of $1 \mathrm{~km}$ ), with the $K$-gradient TKE formulation remaining for other dynamical fluxes and for vertical thermodynamic fluxes within the

PLi $\mathrm{L}$. They performed idealised simulations and compared the thermodynamic fluxes from the kilometre-scale MesoNH simulations with reference vertical profiles of a single cumulonimbus cloud derived from Large Eddy Simulations (1) S) at $200 \mathrm{~m}$ grid length. Verrelle et al. (2017) conclude that a value of $K_{L}=3$ or 4 provides the best fit with the LES P rofiles but highlight the need to evaluate this approach on real cases of deep convection. In this paper we describe the implementation of the contribution to the vertical flux from the Leonard terms in 1 the Met Office's Unified Model (MetUM) and show their impact on real cases of deep and shallow convection over the UK. Unlike Verrelle et al. (2017), who only applied the new scheme to thermodynamic fluxes above the PBL, here pote

b consistent with the variables already modified by the existing UM Smagorinsky scheme, however their impact on

The model precipitation rates is small (not shown). Moeng et al. (2010) also propose horizontal flux terms which have not currently been implemented in the UM. The paper is organised as follows: Section 2 describes the background to the Leonard terms and the tilting terms; Section 3.1 provides an overview of the UM and the experimental setup used helre; Section 3.2 describes a description of how the Leonard terms have been implemented in the UM; results are

\footnotetext{
${ }^{1}$ In fact, as is common in many models, a linearized form is used, $\theta_{l}=\theta-\frac{L}{C_{p} \Pi} q_{c l}$. Since both this and the numerical implementation of the diffusion operator are linear, the same results are obtained as would be if $\theta, q_{v}$ and $q_{w}$ were mixed.
} 
presented in Section 4 firstly for two case studies and secondly for a longer period of one month; and finally discussion and conclusions are presented in Section 5.

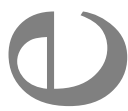

\section{THE LEONARD AND TILTING CONTRIBUTIONS TO TURBULENT FLUXES}

NVNP models need to represent the subgrid-scale mixing and transport of heat and moisture that is unable to be re$r$

I 5 'ved on the model grid. Planetary boundary-layer (PBL) schemes are 1D because they are based on the assumption that ensemble-averaging has been applied to a horizontally homogeneous, statistically stationary flow. Thus, horizontzll gradients and hence horizontal flux divergences are zero. Vertical fluxes may be represented through gradient diffusion, but, especially in convective boundary-layers, counter-gradient term are also often used (and, arguably, are essential in a pure gradient-diffusion formulation (e.g. Gassmann and Herzog, 2015)). With grid lengths of the order $10 \mathrm{~km}$ it is reasonable to suggest that subgrid mixing and transport is best represented by both a convection scheme d a 1D PBL scheme, although several studies (Pearson et al., 2013; Holloway et al., 2013) have shown that some a pects of behaviour such as large-scale convective organisation, are better represented at grid lengths of $12 \mathrm{~km}$ when convection is explicit rather than parameterised. 1

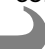

At very high resolution (in practice better than $100 \mathrm{~m}$ grid length) the objective is to represent the large, energy ihing eddies explicitly i.e. perform a large-eddy simulation (LES). One of the most widely used turbulence-closure 1

n dels for LES is the Smagorinsky-Lilly-type first-order-closure scheme based on Smagorinsky (1963); this is based on a notional space/time filtering of the equations of motion and assumes local isotropy and steady-state in the subfilter xes. Such a scheme is three dimensional and isotropic. It represents subfilter scalar fluxes through gradient diffusion d momentum fluxes via an eddy viscosity. Note that Smagorinsky first introduced the scheme for use in larger scale mpdels in two horizontal dimensions, and many NWP and climate models use horizontal Smagorinsky in this context; this should be considered and entirely separate application.

Other schemes exist for use at LES resolutions; most simply the local steady state assumption may be relaxed somewhat in so-called one-and-one-half-order schemes using a prognostic equation for turbulent kinetic energy (TKE), 
but the fundamental assumption is based on gradient diffusion. (Note also that many 'TKE-based' schemes are 1D PBL schemes, not designed for LES use.)

At grid lengths of order $1 \mathrm{~km}$, the turbulence and convective transport is partially resolved so that a conventional Convection scheme is no longer appropriate and a traditional 1D PBL scheme starts to break down as the horizontal grld length approaches the depth of the PBL. This regime was termed the "terra incognita" by Wyngaard (2004) (W04 reafter) or "grey-zone" of turbulence and it has been studied by several authors (e.g. Craig and Dörnbrack, 2008; rodi and Tanelli, 2010; Honnert et al., 2011; Beare, 2013). Designing schemes to address this regime is a considerle challenge. In practice, the pragmatic approach has been taken of using either a 1D PBL or Smagorinsky-Lilly LES crheme despite their inappropriateness. Within the Met Office's UM (MetUM), a scheme has been introduced that ends' between the Smagorinsky scheme and the 1D PBL scheme.

Very high resolution versions of the Met Office's UM use a Smagorinsky-Lilly-type scheme (Halliwell, 2007) where the subfilter fluxes of momentum, $\tau$, and conserved scalars $\chi$, are parametrized as:
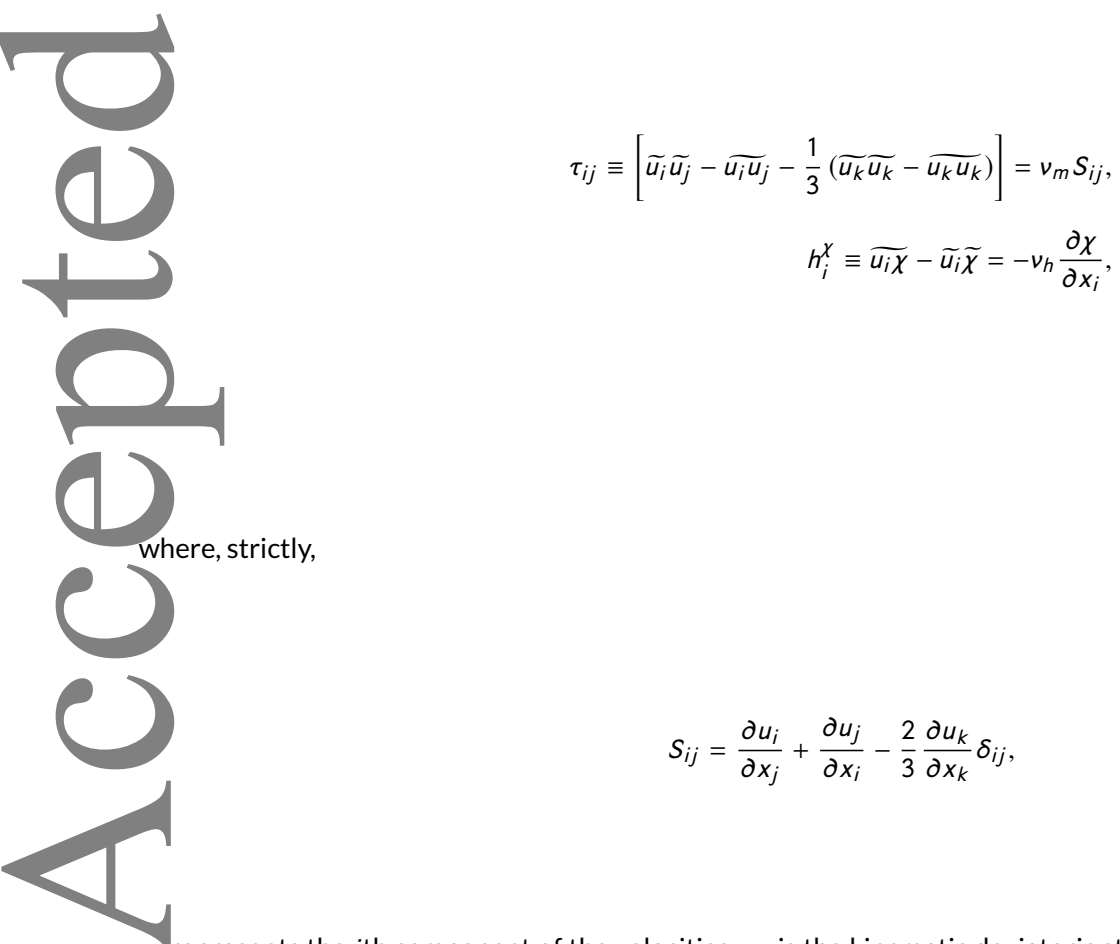

$u_{i}$ represents the $i$ th component of the velocities, $\tau_{i j}$ is the kinematic deviatoric stress and Einstein's summation convention is taken to apply. The tilde operator denotes a notional space/time filter applied to the equations of motion 
rather than filtering applied to real data. As noted by Gassmann and Herzog (2015), the issues surround the precise thermodynamic variables to diffuse; in the MetUM the liquid-water potential temperature and sum of vapour and liqLid are mixed in the vertical and the primary model variables, dry virtual potential temperature and separate moisture Necies are mixed horizontally. It is recognized that this mixture is not ideal but it is convenient for reasons of code utsign and the inconsistencies introduced are negligible. In practice the last term in $S_{i j}$, which removes the trace (i.e. t) divergence of the flow), has not been included in operational code, and velocity components have been treated through simple diffusion, as these terms are close to zero even in a compressible model and including them merely a' ds computational cost while not significantly changing results. In the classical Smagorinsky-Lilly approach the eddy ras viscosity coefficient, $v_{m}$, is defined as:

$$
v_{m}=\left(c_{s} \Delta\right)^{2} S=\lambda_{0}^{2} S
$$

nere $S^{2} \equiv \frac{1}{2} S_{i j} S_{i j}$. Here $c_{s}$ is an empirically determined constant, $\Delta$ is the maximum horizontal grid length, $\lambda_{0}$ is the n xing length and we have implicitly used the Einstein summation convention for tensors. In the UM implementation, ty o extensions are made to the classical approach, reducing the mixing length close to the surface and modifying it to ake into account the dynamical effects of the local Richardson number $\left(R_{i}\right)$ through a Richardson number dependent y functions $f_{m}(R i)$ and $f_{h}(R i)$, with $f_{m}(0)=0$ and $f_{h}(0)=P r_{N}^{-1}$, with $P r_{N}$ the neutral Prandtl number (after Lilly 62)) so that:

$$
v_{m, h}=\lambda^{2} S f_{m, h}(R i)
$$


where

$$
\frac{1}{\lambda^{2}}=\frac{1}{\lambda_{0}^{2}}+\frac{1}{\left[\kappa\left(z+z_{0}\right)\right]^{2}},
$$

ere $z$ is the height above the surface, $z_{0}$ is the roughness length of the surface and $\kappa=0.4$ is the von Kármán constant. xing is applied isotropically, with the same mixing length, $\lambda_{0}=c_{s} \Delta$, used in both the horizontal and the vertical rirections. According to Lilly (1962), for isotropic mixing, $\lambda_{0}$ should have a dependence on the vertical grid length:

$$
\lambda_{0}=c_{s}(\Delta x \Delta y \Delta z)^{1 / 3}
$$

al $d$ hence depend on height in a model with a variable vertical grid spacing. Some studies have been performed in the MetUM for deep convection at $200 \mathrm{~m}$ horizontal resolution that suggest that this change has little impact compared th a fixed length-scale (away from the surface layer) (Halliwell, pers. comm.). However that is beyond the scope of s study. Hanley et al. (2015) showed that convective cells in the UM are very sensitive to $\lambda_{0}$ and by increasing the mixing length in a smaller grid length simulation it is possible to produce a simulation with similar storm morphologies to those in a larger grid-length simulation.
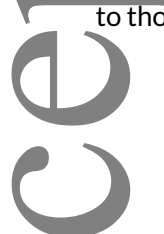

The Smagorinsky-Lilly subfilter turbulence scheme and the non-local PBL scheme of Lock et al. (2000) scheme are ended as described in Boutle et al. (2014). The MetUM PBL scheme also uses a local Richardson number formulation lere the eddy diffusivity,

$$
K_{\chi}=I^{2} S f_{\chi}(R i)
$$


As both schemes use the same stability function, $f_{\chi}(R i)$, and the full 3D wind shear, $S$, the only difference between $K_{\chi}$ and the eddy diffusivity used in the subgrid turbulence scheme is the mixing length, $I$. The mixing lengths from the two schemes are blended using a weighting function, $W_{1 D}$, which tells us how poorly resolved the turbulence is:

$$
I_{b l e n d}=W_{1 D} I+\left(1-W_{1 D}\right) \lambda
$$

function used to blend the schemes is based on the turbulent kinetic energy partition given by Honnert et al. 11):

$$
W_{1 D}=1-\tanh \left(0.15 \frac{z_{h}}{\Delta x}\right) \max \left(0,1-\frac{\Delta x}{4 z_{h}}\right)
$$

where $z_{h}$ is the PBL depth. The Boutle et al. (2014) scheme also contains a non-local component to the turbulent flux, d this is simply down-weighted by W1D to ensure that it becomes less significant as the turbulence becomes better solved. Therefore the full eddy diffusivity is given by

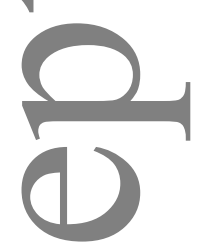

$$
K_{\chi}=\max \left[W_{1 D} K_{\chi}^{N L}, K_{\chi}(R i)\right]
$$

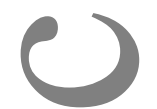

Where $K_{\chi}^{N L}$ is the non-local diffusivity and $I$ in eq. (7) is given by $I_{b l e n d}$ in eq. (8). The turbulent flux is then calculated as

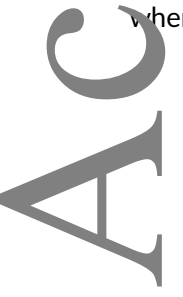

$$
F_{\chi}=-k_{\chi} \frac{\partial \chi}{\partial z}+W_{1 D} F_{\chi}^{N L}
$$


where $F_{X}^{N L}$ is the nonlocal flux. Therefore, when $W_{1 D}=1$, the scheme of Boutle et al. (2014) is recovered, while with $W_{1 D}=0$ the Smagorinsky-type scheme is recovered. The only difference is that diffusion is applied in the horizontal as well as vertical directions; in practice, as horizontal grid length becomes much larger than the boundary-layer mixing ngth, horizontal gradients become small enough that the horizontal mixing is negligible. Blending the two schemes III, this way allows the model to transition from unresolved to resolved turbulence in a plausible way, without the user h ving to decide at which grid length to switch from a 1D, nonlocal, to a 3D, local subgrid scheme.

Thus, the full scheme relies on isotropic eddy diffusivities and vicosities. Any anisotropic (primarily vertical) flux assumed to be carried by large eddies represented only as coarser resolution is approached by the non-local flux tctrms.

The derivation of Smagorinsky-Lilly type subgrid turbulence schemes, such as that used in the UM, are based on a number of assumptions: they assume steady state between shear and buoyant production and dissipation of turbulent stress and scalar fluxes; they ignore the turbulent transport terms on the assumption that the local gradients are gligible; and they ignore the tilting production terms. The tilting terms account for the tilting of horizontal flux into ne vertical by horizontal gradients in vertical velocity (and similarly for vertical fluxes being tilted into the horizontal gradients in the horizontal winds). Wyngaard (2010) points out that there is no reason to ignore the tilting terms as there is no reason to suspect they are negligible.

We can derive an evolution equation for the $i$ th component of subfilter flux of scalar $c$ in a Boussinesq fluid, $\tau_{u_{i} c} \equiv$ $u_{i} c-u_{i j} \tilde{c}$. Using the notation of Moeng et al. (2010) this is

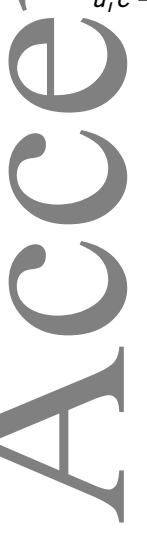

$$
\begin{aligned}
\frac{\partial \tau_{u_{i} c}}{\partial t}+\widetilde{u_{k}} \frac{\partial \tau_{u_{i} c}}{\partial x_{k}}= & \frac{\partial}{\partial x_{k}}\left(\widetilde{c u_{i} \widetilde{u_{k}}}-\widetilde{c u_{i} u_{k}}+\widetilde{c u_{i} u_{k}}+\widetilde{u_{i}} \widetilde{c u_{k}}-2 \widetilde{c u_{i} \widetilde{u_{k}}}\right) \\
& +\frac{\partial}{\partial x_{k}}\left\{v\left[\overline{\frac{\partial u_{i}}{\partial x_{k}}}-\widetilde{c} \frac{\partial \widetilde{u_{i}}}{\partial x_{k}}\right]+D\left[\widetilde{u_{i} \frac{\partial c}{\partial x_{k}}}-\widetilde{u_{i}} \frac{\partial \widetilde{c}}{\partial x_{k}}\right]\right\} \\
& -R_{i k} \frac{\partial \widetilde{c}}{\partial x_{k}}-\tau_{u_{k} c} \frac{\partial \widetilde{u_{i}}}{\partial x_{k}}+\delta_{i 3}(\widetilde{c b}-\widetilde{c b}) \\
& +\widetilde{u_{i} S^{c}}-\widetilde{u_{i}} \widetilde{S^{c}}-2 \varepsilon_{c} \\
& -\frac{1}{\rho} \frac{\partial}{\partial x_{i}}(\widetilde{p c}-\widetilde{p c})+\frac{1}{\rho} p \frac{\partial c}{\partial x_{i}}-\frac{1}{\rho} \widetilde{p} \frac{\partial \widetilde{c}}{\partial x_{i}}
\end{aligned}
$$


where we have used the Einstein summation convention for suffices, $R_{i k}=\widetilde{u_{i} u_{k}}-\widetilde{u_{i}} \widetilde{u_{k}}$ and $b$ is the buoyancy.

The left hand side represents the material rate of change of the flux following the fluid. The first two lines on the

(1) 'rht-hand-side represent divergences of fluxes and so are 'transport' terms. The third row contains production terms; Trom left to right: production through the shearing of the mean scalar gradient, the 'tilting' term wherein the flux in one direction is 'tilted' by along-flux gradients of the cross flow, and the buoyant production. The next line contains oduction through other sources of scalar $c, S^{c}$, and the molecular dissipation:

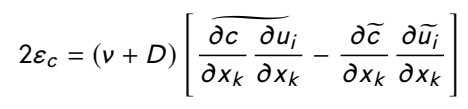

THe last line comprises pressure terms.

This is similar to eq. (18) of W04 with the addition of molecular viscosity diffusivity terms (which they neglect) and th : buoyant production term. The first pressure term is often considered negligible (e.g. Mellor (1973)) or as another (1) I

source or sink (or both). W04 treats it as sink, $-\tau_{u_{i} c} / T$. It may be much larger than the molecular dissipation rate, but Whatever its magnitude it can be combined with the dissipation rate. Any source contribution is often assumed to be in Constant proportion with the other source terms (leading to additional closure constants, e.g. Nakanishi (2001)); in narticular, the buoyancy-flux component essentially balances the additional buoyant production term in the vertical

Thus, ignoring the transport and scalar flux terms, assuming steady state on an air parcel and replacing the presre destruction terms with decay terms the equation for scalar flux becomes:

$$
\frac{\tau_{u_{i} c}}{T}=-R_{i k} \frac{\partial \widetilde{c}}{\partial x_{k}}-\tau_{u_{k} c} \frac{\partial \widetilde{u_{i}}}{\partial x_{k}}
$$

This is essentially eq. (19) of W04 rearranged slightly. As W04 points out, the solution to this can formally be written 
as a down-gradient diffusion with tensor rather than scalar diffusivity.

The $R_{i k}$ term can be written:

$$
R_{i k}=\frac{2}{3} e \delta_{i k}-\tau_{i k}^{d}
$$

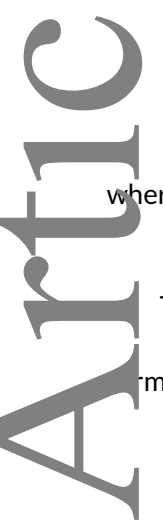

The Smagorinsky-Lilly scheme only retains the homogeneous part of this first term and also neglects the tilting m in eq. (14), leading to $v_{h}=\frac{2}{3} e T$. If we also retain the tilting term in the scalar flux terms we obtain:

$$
\tau_{u_{i} c}=-v_{h} \frac{\partial \widetilde{c}}{\partial x_{i}}-\tau_{u_{k} c} T \frac{\partial \widetilde{u_{i}}}{\partial x_{k}}
$$

is can be solved as a set of simultaneous equations. If we write $f_{i}=\tau_{u_{i} c}, a_{i}=-v_{h} \frac{\partial c^{r}}{\partial x_{i}}, b_{i j}=T \frac{\partial \widetilde{u_{i}}}{\partial x_{j}}$ then eq. (16) be written $(\mathbf{I}+\mathbf{b}) \mathbf{f}=\mathbf{a}$. This has the straightforward solution $\mathbf{f}=(\mathbf{I}+\mathbf{b})^{-1}$ a but it is quite complex, would be re atively expensive to evaluate and gives us no insight into the characteristics of the solution. It is useful to pursue an approximate solution.

If we consider the budget equation for TKE, assuming steady state and ignoring the transport terms, we can write

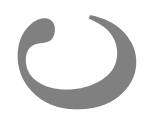

If we consider the budget equation for TKE, assuming steady state and ignoring the transport terms, we can write

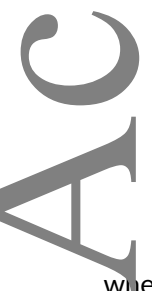

$$
\varepsilon=\frac{1}{2} \tau_{i k}^{d} S_{i k}+\tau_{w b}
$$

Where $\tau_{w b}$ is the buoyancy flux. If $\tau_{i k}^{d}=S_{M} e^{\frac{1}{2}} \lambda S_{i j}$, a standard eddy diffusion closure, and $\varepsilon=e^{\frac{3}{2}} /\left(k_{\varepsilon} \lambda\right)$, with $k_{\epsilon}$ a constant, then, in neutral conditions, $e \sim S_{M} k_{\varepsilon} \lambda^{2} S^{2}$. Likewise, if $v_{h}=S_{H} e^{\frac{1}{2}} \lambda, T=k_{c} \lambda / e^{\frac{1}{2}}$, and $k_{c}$ a constant (so 
$\left.k_{c}=\frac{3}{2} S_{H}\right)$, we can write, at least in neutral conditions

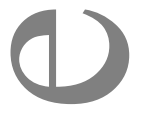

$$
|\mathbf{b}|=\left|T \frac{\partial \widetilde{u}_{i}}{\partial x_{j}}\right|=\left|\frac{k_{c} \lambda}{e^{\frac{1}{2}}} \frac{\partial \widetilde{u}_{i}}{\partial x_{j}}\right|=\frac{k_{c}}{\left(S_{M} k_{\varepsilon}\right)^{\frac{1}{2}}}\left|\frac{\frac{\partial \widetilde{u}_{i}}{\partial x_{j}}}{S}\right|=\frac{\frac{3}{2} S_{H}}{\left(S_{M} k_{\varepsilon}\right)^{\frac{1}{2}}}\left|\frac{\frac{\partial \widetilde{u}_{i}}{\partial x_{j}}}{S}\right|
$$

early, $\left|\frac{\partial \widetilde{u}_{i}}{\partial x_{j}} / S\right| \leq 1$. In the surface layer it is straightforward to show that, with $\lambda=\kappa z, \kappa$ being the von Kármán nstant, $S_{M} k_{\varepsilon}=e / u_{*}^{2}$, with $u_{*}$ the friction velocity. Various estimates exist for this, but all are $\mathrm{O}(10)$, so if we assume cris is a universal constant relating dissipation to mixing length, it is clear that (with $S_{H}=O(1)$ ) $|\mathbf{b}|<1$.

More sophisticated analysis is possible but the essential point is that so long as the tilting production term does not exceed the dissipation in magnitude we can assume $|\mathbf{b}|<1$. In unstable conditions, the buoyancy production furer increases the TKE, so reducing $b$. We conclude that only in stable conditions might the scalar fluxes be markedly dominated by the tilting terms and it is reasonable to assume that in neutral and unstable conditions $|\mathbf{b}|<1$. We now us ? the identity $(\mathbf{I}+\mathbf{b})^{-1}=\mathbf{I}-\mathbf{b}(\mathbf{I}+\mathbf{b})^{-1}$ to arrive at:

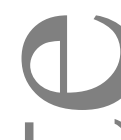

$$
\mathbf{f}=\mathbf{a}-\mathbf{b}(\mathbf{I}+\mathbf{b})^{-1} \mathbf{a}=\mathbf{a}-\mathbf{b} \mathbf{a}+\mathbf{b}^{2}(\mathbf{I}+\mathbf{b})^{-1} \mathbf{a}=\mathbf{a}-\mathbf{b} \mathbf{a}+\mathbf{b}^{2} \mathbf{f}
$$

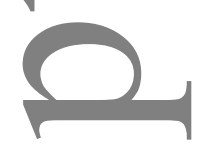

This could be continued to the usual series expansion of $(\mathbf{I}+\mathbf{b})^{-1}$ but this approach is a little more instructive. Considering the last term a negligible correction $\left(|\mathbf{b}|^{2} \ll 1\right.$, i.e. $\left.\left.(\mathbf{I}+\mathbf{b})^{-1} \approx(\mathbf{I}-\mathbf{b})\right)\right)$ then eq. (16) becomes

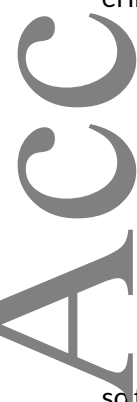

(1)

solthe flux in the tilting term is approximated by the usual gradient diffusion and the 'tilting of tilting' is neglected. Note that this result suggests that the tilting term cannot be large enough to change the direction of the flux. 
In the context of a boundary layer, where horizontal fluxes are non zero but non-divergent, we are primarily interested in the vertical flux. The above gives us:

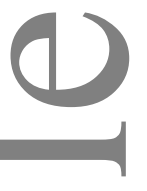

$$
\tau_{w c}=-v_{h}\left(1-T \frac{\partial \widetilde{w}}{\partial z}\right) \frac{\partial \widetilde{c}}{\partial z}+v_{h} T\left(\frac{\partial \widetilde{c}}{\partial x} \frac{\partial \widetilde{w}}{\partial x}+\frac{\partial \widetilde{c}}{\partial y} \frac{\partial \widetilde{w}}{\partial y}\right)
$$

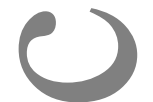

e correction to the first term on the right is likely to be small in the boundary layer and can probably be ignored. $1)$ e second term represents tilting of horizontal fluxes into the vertical direction. With the above assumptions, $v_{h} T=$ ${ }_{H}^{2} \lambda^{2}$. The coefficient depends only on the filter scale (squared), and stability constant and not on the TKE or shear. haturally leads to the idea that it is tilting by structures close to th efilter scale that have most impact on this flux.

\footnotetext{
Moeng et al. (2010) propose an extension to the Smagorinsky-Lilly scheme to be applied in the vertical. They rametrize the sub-grid fluxes, of some variable $\Phi$, as a combination of down-gradient turbulent mixing (SmagorinskyL 'y/local PBL) and near-grid-scale unresolved fluxes related to horizontal gradients in vertical velocity and the transported scalars:

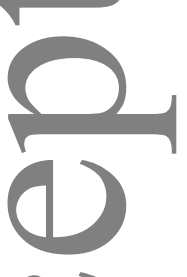

$$
\tau_{w \Phi}=-v_{\chi} \frac{\partial \Phi}{\partial z}+\frac{K_{L}}{12}\left(\Delta x^{2} \frac{\partial w}{\partial x} \frac{\partial \Phi}{\partial x}+\Delta y^{2} \frac{\partial w}{\partial y} \frac{\partial \Phi}{\partial y}\right)
$$

he second term on the right-hand side (referred to as the Leonard term: Leonard (1974); Moeng et al. (2010)) repents the contribution to the sub-grid fluxes from the largest subgrid-scale eddies (i.e. the eddies that have scales s' hilar to the horizontal resolution of the model). The parameter $K_{L}$ is a constant which is used to scale the Leonard term fluxes. A value of 1.0 yields just the Leonard term. Moeng et al. (2010) suggest a value of $K_{L}=2$ as they found that a significant fraction of other turbulent flux terms are highly correlated with the Leonard term. In a more recent study, Moeng (2014) propose a value of $K_{L}=5$. 
The Leonard term in eq. (22) has a very similar form to the tilting term in eq. (21). They are the same if

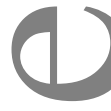

$$
\frac{3}{2} S_{H}^{2} \lambda^{2}=\frac{K_{L}}{12} \Delta x^{2}
$$

we make the usual Smagorinsky assumption, eq. (3), the grid length squared appears in both the tilting and Leonard $\cdots-m s$ and $K_{L}$ depends only on the stability function and $c_{s}$. The derivation from the tilting terms is not inconsistent 1 with the derivation from the Leonard terms and we may, in some sense, associate the two. Indeed it seems reasonable suggest that the tilting term may act most strongly on the largest subgrid-scale eddies.

Beyond the derivation leading to eq. (21) it is difficult to make precise comparisons with the derivation by Moeng et al. (2010) because the comparison depends on the relationships between the mixing length, $\lambda$, the filter scale, $\Delta_{f}$ and the grid spacing $\Delta x$. However, taking their formulation directly, $S_{H} \equiv(1+2 \ell / \Delta) c_{K}$ with $\lambda \equiv \ell=\Delta=\left(\Delta_{f}^{2} \Delta z\right)^{\frac{1}{3}}$ neutral conditions (which means $\Delta$ varies with height). With $\Delta_{f}=4 \mathrm{~km}$ and $\Delta x=1 \mathrm{~km}$, if $\Delta z=150 \mathrm{~m}$, say, then $=928 \mathrm{~m}$. Even with $\Delta z=50 \mathrm{~m}, \Delta=928 \mathrm{~m}$, so the mixing lengths used are close to or larger than the notional model d length of $1 \mathrm{~km}$. Thus with $c_{K}=0.4$ the coefficient in the second term becomes $\frac{3}{2} 1.2^{2} \Delta^{2} \approx 26 / 12 \Delta^{2}$ However, the Cl oice of mixing length here seems very large when compared with typical LES practice (where $\lambda$ is a fraction of $\Delta x$, t a fraction of a multiple of $\Delta x$ ) and it seems likely that there is some inconsistency between the filter scale and exact of mixing length. If we use values more typical of a Smagorinsky-Lilly formulation, we arrive at an estimate t $\mathrm{o}$ orders of magnitude smaller. Thus, the appropriate choice of $K_{L}$ is very sensitive to the relationship between -mixing length, grid length and filter scale, and, furthermore, is likely to be model-dependent. While a more in-depth erivation, not given here, suggests that $K_{L}$ close to 1 is, indeed, appropriate, it seems prudent to regard this as a t) heable parameter with the caveat that doing so may lose any guarantee that the flux direction is not reversed.

The same approach can be taken with the deviatoric stress, starting with the steady-state budget and assuming that the stress has a leading order term given by the eddy diffusivity; due to the tensor nature of the stress the result is more complex and will not be repeated here. However, it contains additional terms with much the same flow derivative products with similar coefficients (i.e. length-scale squared). When simplified to the context of a 1D boundary-layer, 
they contain terms similar to the Leonard terms proposed by Moeng et al. (2010). Since we have not used these stress terms in this paper, this be the topic of a future publication.

\section{3 | METHODOLOGY}

\section{1 | Model description}

1 me numerical experiments are performed using the Met Office's UM Version 10.7. The UM is the Met Office's operanal NWP model and is used to provide global and regional deterministic and ensemble forecasts. The model solves n-hydrostatic, deep-atmosphere dynamics using a numerical scheme which is semi-implicit and semi-Lagrangian (Davies et al., 2005; Wood et al., 2014). The model uses a regular latitude-longitude grid in the horizontal with Arakawa C staggering and a terrain-following hybrid-height Charney-Phillips grid in the vertical. For limited area configurans, the pole of the grid is rotated such that the domain is approximately centred on the equator, in order to minimise langes in grid length across the domain. The model uses a comprehensive set of parameterisations including the face-layer scheme of Best et al. (2011), the mixed-phase cloud microphysics scheme of Wilson and Ballard (1999) a) d the non-local PBL scheme of Lock et al. (2000). There is also a convection scheme based on Gregory and Rownree (1990), although this is switched off at grid lengths of $2.2 \mathrm{~km}$ and finer. As described in Section 2, the model also s a Smagorinsky-type subgrid turbulence scheme.

The current Met Office deterministic operational nested suite consists of three configurations: Global; European 4 km (Euro4) and UK Variable-resolution (UKV). Global analyses are produced four times a day using a hybrid increnental 4D-Var data assimilation system (Rawlins et al., 2007) and the Global Atmosphere version 6.1 (GA6.1) science hfiguration (Walters et al., 2017). The UKV model is a limited-area, variable resolution configuration of the UM n'sted within the global model. The inner part of the domain covers the entire UK (shown in Fig. 1) and has a horizontal grid length of $1.5 \mathrm{~km}$. The outer region has a horizontal grid length of $4 \mathrm{~km}$ and in between there is a variableresolution transition region. The variable resolution allows the boundaries of the UKV to be further from the UK at a cheaper computational cost than if the domain had a fixed resolution of $1.5 \mathrm{~km}$. In the vertical, the UKV has 70 levels, 


\section{(1)

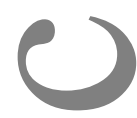

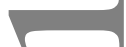

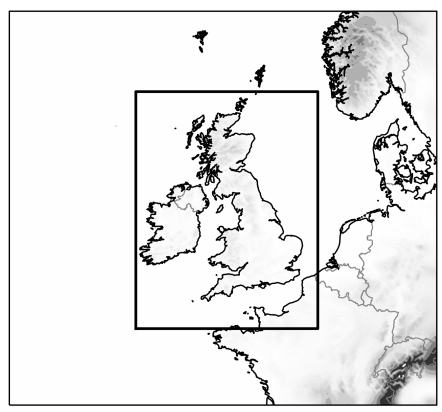

'GURE 1 The UKV model domain. The inner $1.5 \mathrm{~km}$ grid length part of the domain is indicated by the black line.

Orography is shown in grey-scale.

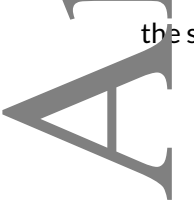

the spacing of which increases quadratically with height up to the domain top at $40 \mathrm{~km}$.

The Leonard terms have been implemented in the UM (as described in section 3.2) and tested using the UKV model. the UKV simulations, the 0000 UTC operational GA6.1 analysis was used as initial conditions, with lateral boundary

c nditions provided by the 0000 UTC GA6.1 model forecast. The global analysis was used rather than the UKV analysis I as the UKV domain was extended in November 2016 so the UKV analysis for the cases chosen was not available on the current domain. The UKV simulations are integrated forward for 24 hours using a $60 \mathrm{~s}$ timestep. The setup of the W V V id that which was operational in winter and spring 2017 (called Operational Suite 38 or OS38).

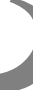

A selection of spring and summer convective cases from 2016 were run with the UKV. The results are split into o sections as follows. In the first section we focus on two case studies: one spring event (30 April 2016) and one 'mmer event (15 June 2016). Statistics such as number and size of storms, domain-averaged precipitation rate and histograms of rainfall rate were produced for these cases. In the second section we focus on rainfall statistics for a longer period, covering 21 July - 21 August 2016. In both sections the analysis was performed over a region covering the southern half of the UK as this was where the precipitation occurred in the chosen cases. 


\section{2 | Implementing the Leonard terms}

T e differential equations for the terms we are trying to compute are, for some variable $\Phi$ :

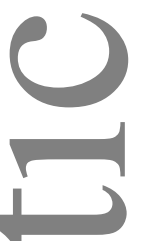

$$
\tau_{w \Phi}=\frac{K_{L}}{12}\left(\Delta x^{2} \frac{\partial w}{\partial x} \frac{\partial \Phi}{\partial x}+\Delta y^{2} \frac{\partial w}{\partial y} \frac{\partial \Phi}{\partial y}\right)
$$

In discretising these expressions, the grid-lengths cancel out so that the fluxes are purely based on the finite differences, rather than actual gradients.

The discretisation is not straightforward, due to the horizontal and vertical grid staggering used in the UM. The method adopted here calculates the desired finite differences (and hence fluxes) over each of the 8 grid-volumes neighgruring the point where we want the flux, and then averages them together as shown in Fig. 2.
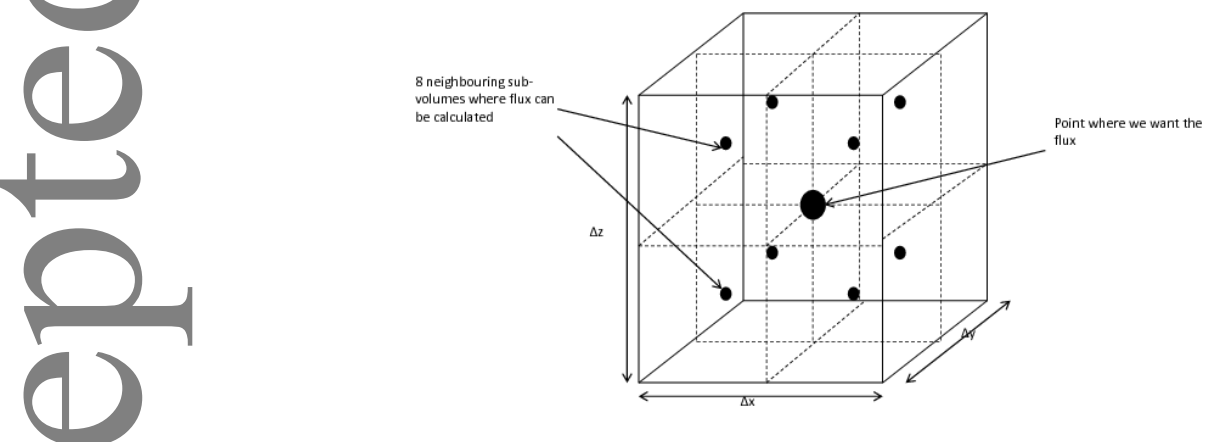

FIGURE 2 Schematic showing the points where the Leonard flux is calculated on the UM grid.

A forward in time, centered in space discretisation is used. Linear stability analysis shows that this discretisation II not have growing solutions that oscillate in time provided:

$$
\Delta t<\left|\frac{6}{K_{L}} \frac{\Delta z}{\Delta w}\right|
$$


When setting the Leonard parameter $K_{L}$, it is important to make sure that the choice of value is such that the scheme remains numerically stable. The stability analysis in equation 25 is used to determine the maximum value of $K_{L}$ at each grid point that maintains a stable scheme. If the maximum allowed value of $K_{L}$ is less than the chosen value of $K_{L}$ then e scheme will use this value instead.

In the following section we show the impact of adding the Leonard terms in the UKV for real cases of deep and

allow convection. The control setup is OS38. For each case four additional UKV configurations have been run which in lude the vertical Leonard term fluxes calculated with $K_{L}=1,2,4$ and 6 respectively. Intuitively we expect that Leonard terms will act to reduce horizontal gradients, leading to reduced peak vertical velocities. This will reduce the condensation rates leading to a reduction in peak rainfall rates. Increasing the magnitude of the Leonard term by in treasing $K_{L}$ will amplify this effect.

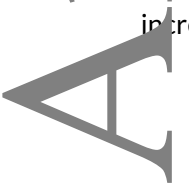

\section{3 | Observations}

e observations used for model verification come from the Met Office radar rainfall composite (Harrison et al., 2011). e radar reflectivity data consists of 5-minute scan sequences of four elevations from the $15 \mathrm{C}$-band radars across the UK, at a resolution of $600 \mathrm{~m}$ in range and $1^{\circ}$ in azimuth. The current rainfall retrieval uses only single-polarisation radar data, thus rainfall rates are estimated from an empirical relationship between radar reflectivity $Z\left(\mathrm{~mm}^{6} \mathrm{~m}^{-3}\right)$ and infall rate $R\left(\mathrm{~mm} \mathrm{hr}^{-1}\right)$ :

$$
Z=200 R^{1.6}
$$

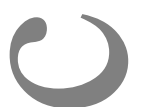

'ich is the Marshall et al. (1955) relationship derived for mid-latitude stratiform rain. Several steps are incorporated in the rainfall-estimation quality control procedure to correct for radar artefacts (e.g. noise filtering, clutter identification, and beam blockage) and an adjustment factor is then applied to all surface rainfall rates, based on comparisons with rain-gauge data (Harrison et al., 2009). The radar rainfall composite is then generated on a $1 \times 1 \mathrm{~km}$ grid from 
these adjusted estimates. Here the radar composite has been regridded to the $1.5 \mathrm{~km}$ UKV grid for a fairer comparison. Further to this, as we do not expect the UKV to be able to accurately represent the rainfall rates at the grid-scale, when plotting histograms of rainfall rate both the model and the radar composite have been regridded to a scale that expect the model to be better able to resolve: $6 \Delta x=9 \mathrm{~km}$.

\section{RESULTS}

\subsection{Case studies}

30 April 2016 widespread showers developed over England and Wales in north-westerly flow. Some of these showers were very intense with reports of inch-deep hail in Cheshire. The control O0Z UKV run captured the initiation time of the showers and their extent, however the cores of the showers were too intense and there was a lack of light rain. Iuding the vertical Leonard term fluxes reduced the peak rainrates slightly but didn't increase the amount of light ain. Figure 3 shows the instantaneous surface rainfall rate at 1100 UTC on 30 April 2016 for the four simulations c npared with the radar composite. All of the simulations capture the main location of the showers, with the largest, most intense showers being in north Wales and the west Midlands and smaller lighter showers elsewhere. The timing f convective initiation and decay is also well represented by the simulations (Fig. 4). The most notable difference bethe simulations and the radar is that the simulations have more regions with high surface precipitation (above $4 \mathrm{~m} \mathrm{hr}^{-1}$ ) and less light precipitation (below $1 \mathrm{~mm} \mathrm{hr}^{-1}$ ) than observed by the radar.

Including the Leonard term fluxes has not affected the evolution of the simulated storms, but there are some diferences in the detail of the storms. From Fig. 3, the simulations with the vertical Leonard term fluxes computed apar to have fewer grid points with high rainrates than the control simulation. This has been quantified in Fig. 5 which ows the histogram of surface rainfall rates between 0900 UTC and 2100 UTC on 30 April 2016 for the five simulations compared with the radar composite. This time period has been chosen to allow the $1.5 \mathrm{~km}$ UKV fields time to spin-up from the lower-resolution initial conditions. As expected based on Fig. 3, all of the simulations under-estimate the number of grid points with light rain. The control simulation overestimates the number of grid points with rain- 

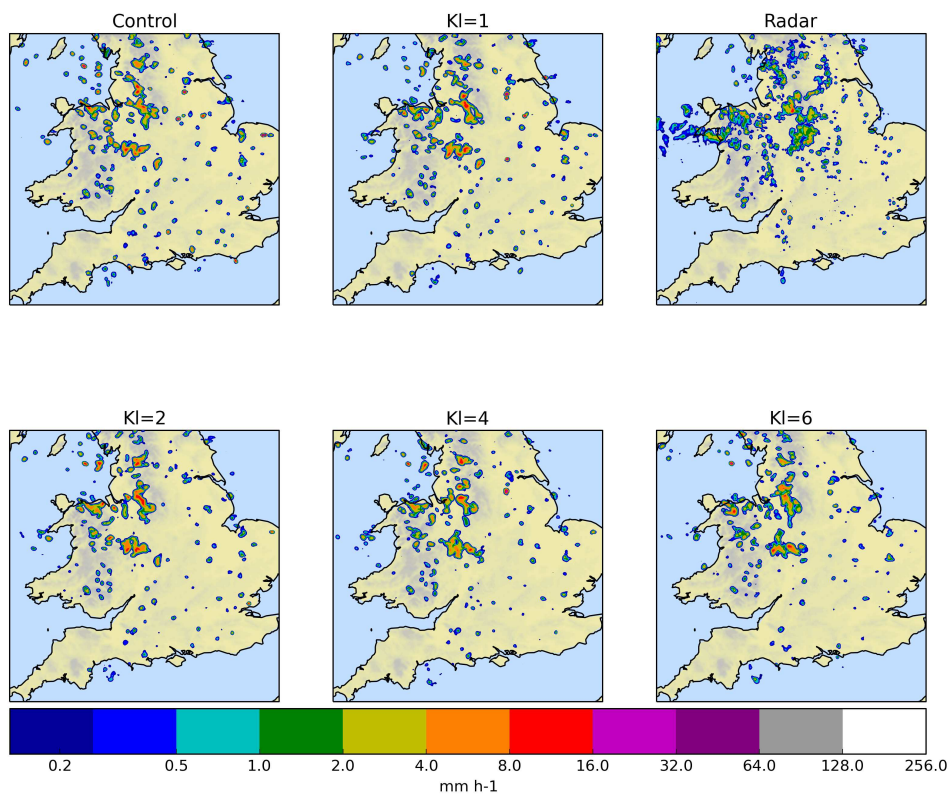

GURE 3 Surface rainfall rate in $\mathrm{mm} \mathrm{hr}^{-1}$ at 1100 UTC on 30 April 2016 for the control UKV simulation and the fo ir additional simulations which include the vertical Leonard term fluxes calculated with $K_{L}=1,2,4$ and 6 espectively compared with the radar-derived surface rainfall composite.
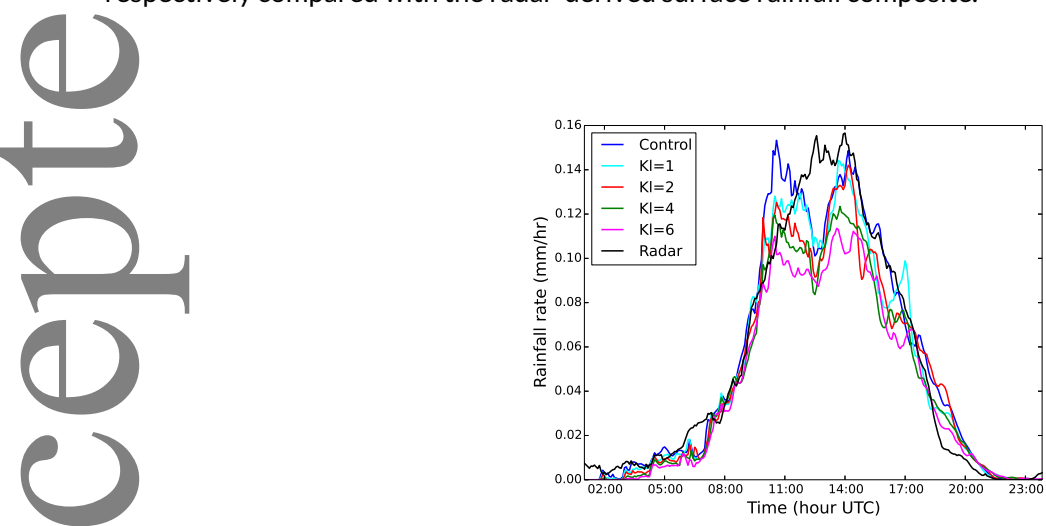

GURE 4 Domain-averaged surface rainfall rate in $\mathrm{mm} \mathrm{hr}^{-1}$ for $30 \mathrm{April} 2016$ for the control UKV simulation and e four additional simulations which include the vertical Leonard term fluxes calculated with $K_{L}=1,2,4$ and 6 respectively compared with the radar-derived surface rainfall composite.

fall rates above $4 \mathrm{~mm} \mathrm{hr}^{-1}$ and has an order of magnitude overestimate of the number of grid points with rainrates above $32 \mathrm{~mm} \mathrm{hr}^{-1}$. As a result the control simulation has the best representation of the domain-averaged precipita- 


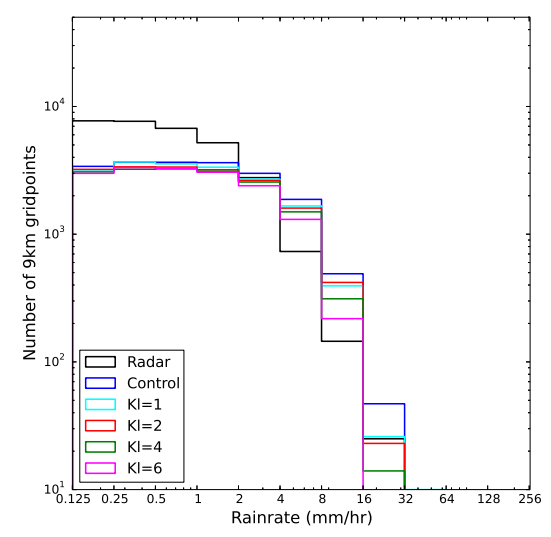

GURE 5 Histogram of surface rainfall rates in $\mathrm{mm} \mathrm{hr}^{-1}$ for $\mathrm{T}+9-\mathrm{T}+2130$ April 2016 for the control UKV sirnulation and the four additional simulations which include the vertical Leonard term fluxes calculated with $K_{L}=1$, 4 and 6 respectively compared with the radar-derived surface rainfall composite. All data has been regridded to $9 \mathrm{~km}$.

tion (Fig. 4), even though the distribution of rainfall rates is poorly represented. Switching on the vertical Leonard rm fluxes reduces the number of grid points with rainrates above $4 \mathrm{~mm} \mathrm{hr}^{-1}$ but has little impact on the light rain${ }_{1}$ rates, leading to lower values of domain-averaged precipitation. Increasing $K_{L}$ further reduces the number of grid $p$ ints with high rainrates, as a result the $K_{L}=6$ simulation lies closest to the radar observations for the rainfall rates

distribution but the domain-average precipitation is furthest from observations in this simulation.

Fis. 6 shows vertical profiles of the horizontally-averaged vertical fluxes of moisture from the Leonard term, the ratended

b'ended PBL scheme and the resolved flow. The resolved moisture flux is calculated as the instantaneous difference between the total transport and transport by the mean fields:

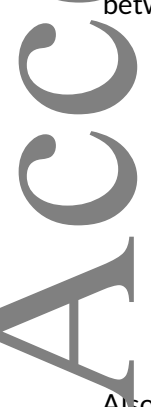

Also shown is the total parameterised vertical flux of moisture, which is the sum of the Leonard term flux and the blended PBL flux, the total vertical flux of moisture, which is the sum of the parameterised flux and the resolved 
flux, and the domain-mean updraught vertical velocity. Encouragingly, the shape of the Leonard moisture flux profile
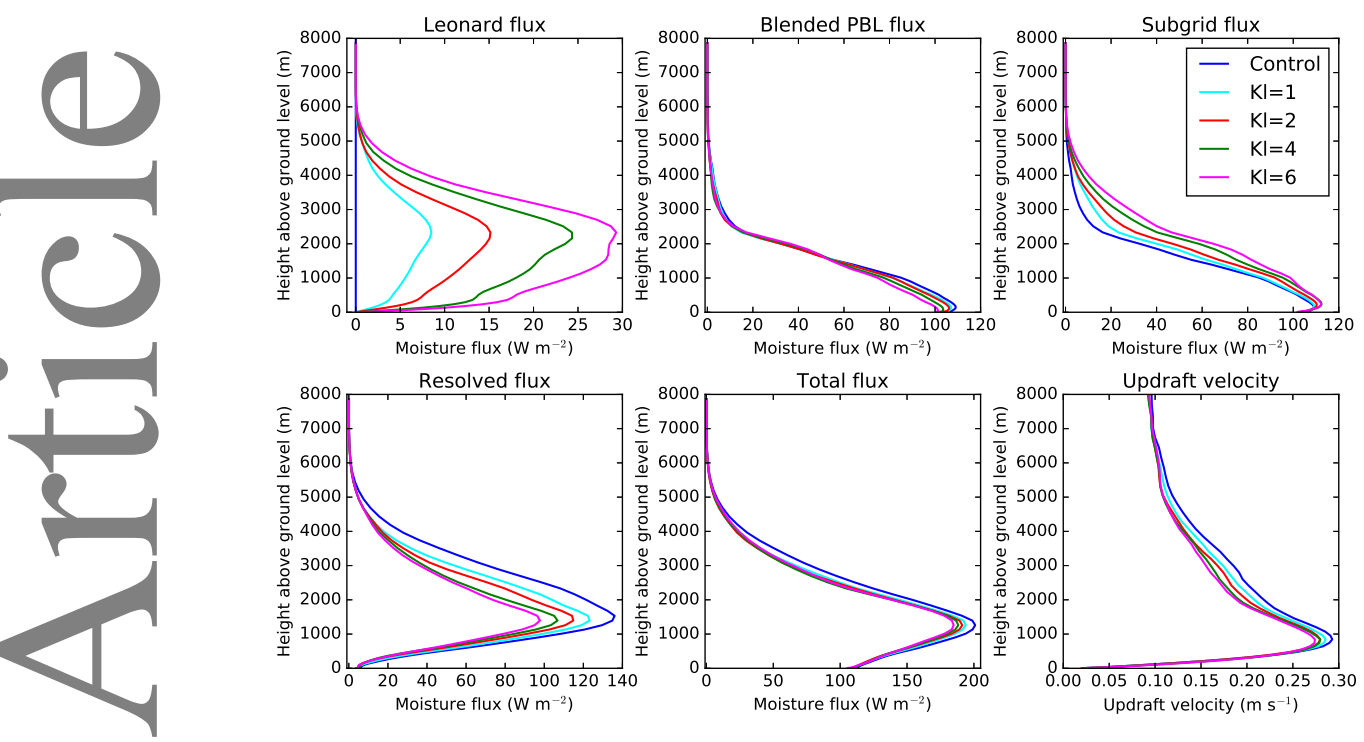

FUGURE 6 Vertical profiles of domain-mean moisture flux $\left(\rho L_{v} \overline{w^{\prime} q_{w}^{\prime}}\right)$ in $\mathrm{W} \mathrm{m}^{-2}$ and updraught velocity (ignoring gions where vertical velocity is less than zero) in $\mathrm{m} \mathrm{s}^{-1}$ for 1100 UTC 30 April 2016 for the control UKV simulation a $\mathrm{d}$ the four additional simulations which include the vertical Leonard term fluxes calculated with $K_{L}=1,2,4$ and 6 respectively. Showing the Leonard term flux, the blended PBL flux, the parameterised flux (Leonard term + PBL), the

I solved flux and the total flux (parameterised + resolved)

atches those of both Moeng et al. (2010) and Verrelle et al. (2017), with a positive flux which peaks within the cloud

la er. As expected, increasing the magnitude of $K_{L}$, increases the magnitude of the Leonard term moisture flux. In contrast, the blended PBL flux decreases with increasing $K_{L}$ within the PBL, above the PBL the flux is similar in all the simations. Due to the Leonard flux peaking higher up than the blended PBL flux, the parameterised flux increases with ii creasing $K_{L}$ with the largest difference between the simulations occurring in the cloud layer. The resolved moisture flux decreases with increasing $K_{L}$ as a result of decreasing the domain-mean vertical velocity. The resolved moisture $x$ decreases more with increasing $K_{L}$ than the parameterised moisture flux increases, resulting in the total moise flux decreasing with increasing $K_{L}$. Therefore the reduction in peak rainfall rates seen in Fig. 5 when increasing the magnitude of the Leonard term fluxes comes from a reduction in both the total vertical flux of moisture and the (10mai domain-mean updraft vertical velocity in the PBL and lower troposphere. 
Fig. 5 showed that including the Leonard term fluxes reduces the number of grid points with rainfall rates above $4 \mathrm{~mm} \mathrm{hr}^{-1}$, but it does not quantify whether it is the size or the number of storms with cores above $4 \mathrm{~mm} \mathrm{hr}^{-1} \mathrm{which}$ is overestimated. To do this Fig. 7 shows the distribution of equivalent storm diameter for 30 April 2016, with storms entified using a rain-rate threshold of $4 \mathrm{~mm} \mathrm{hr}^{-1}$ and an area threshold of four UKV grid boxes (9 km²). From Fig. 7
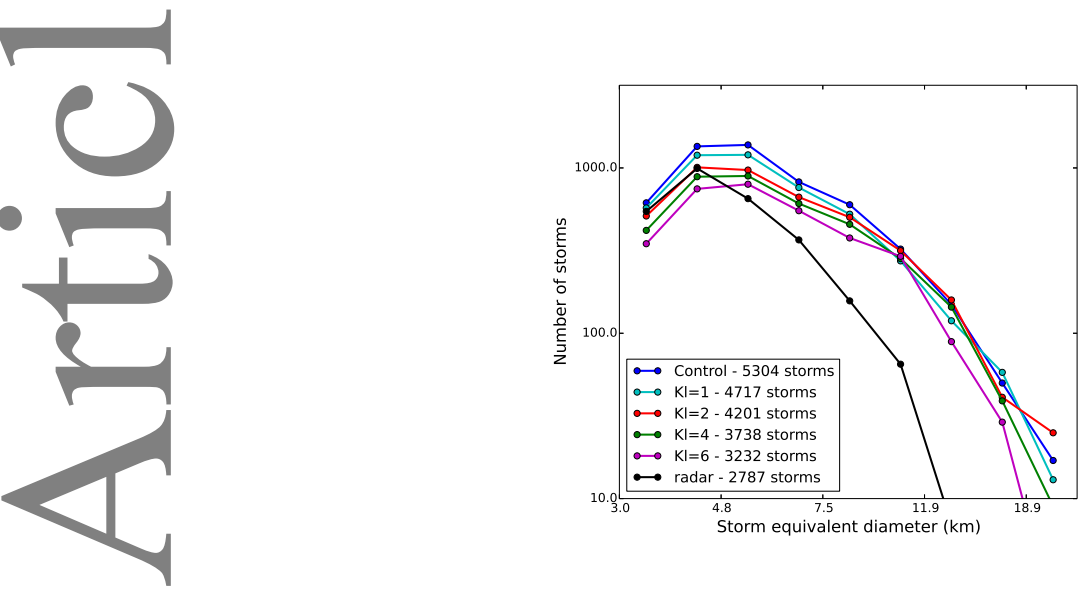

FIGURE 7 Distribution of equivalent storm diameter for 30 April 2016 for the radar composite, the control UKV simulation and the four additional simulations which include the vertical Leonard term fluxes calculated with $K_{L}=1$, 1 and 6 respectively. A rainrate threshold of $4 \mathrm{~mm} \mathrm{hr}^{-1}$ and an area threshold of four UKV grid boxes $\left(9 \mathrm{~km}^{2}\right) \mathrm{have}$ b en used to identify storms. Data are every 5 minutes between 0900 and 2100 UTC.

see that the control UKV simulation has too many storms of all sizes with rainfall rates above $4 \mathrm{~mm} \mathrm{hr}^{-1}$ as well storms with much larger contiguous regions of greater than $4 \mathrm{~mm} \mathrm{hr}^{-1}$ rain-rates than observed by the radar comp site. Including the Leonard term fluxes and increasing $K_{L}$ reduces the number of storms with rainfall rates above $4 \mathrm{~mm} \mathrm{n}^{-1}$ and also reduces the size of contiguous regions of greater than $4 \mathrm{~mm} \mathrm{hr}^{-1}$ rain-rates. However, with $K_{L}=4$ $\mathrm{d} 6$ there are too few small storms with rain-rates above $4 \mathrm{~mm} \mathrm{hr}^{-1}$ and the diameter of the largest storms are still crestimated by almost a factor of 2 .

On 15 June 2016 convective storms developed over England and Wales due to a low pressure system and assoIted upper level troughs which were situated over the UK. As in the previous case, the control OOZ UKV simulation captured the location of the showers however the showers were in general too intense. Again, the main impact of including the vertical Leonard term fluxes was a reduction in the number of grid points with very high rainrates. Figure 8 shows the instantaneous surface rainrate at 1600 UTC on 15 June 2016 for the four simulations compared with the 
radar composite. All of the simulations capture the general area and extent of the showers, however the cells in the
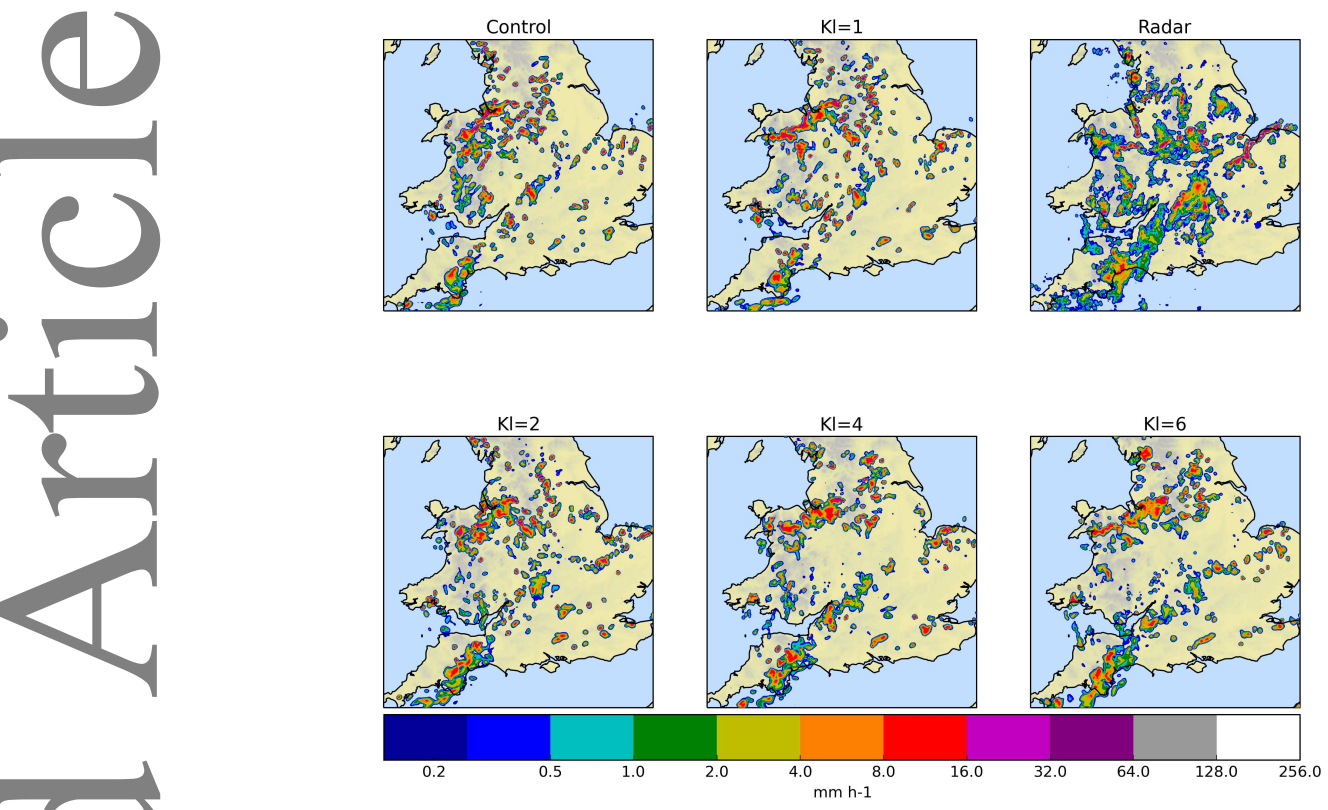

FIGURE 8 Surface rainfall rate in $\mathrm{mm} \mathrm{hr}^{-1}$ at 1600 UTC on 15 June 2016 for the control UKV simulation and the

f $u r$ additional simulations which include the vertical Leonard term fluxes calculated with $K_{L}=1,2,4$ and 6 spectively compared with the radar-derived surface rainfall composite.

\section{1}

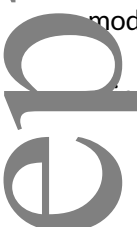

nodel tend to be too circular compared to those observed by the radar with too much heavy rain and not enough light tween the convective cores.

Figure 9 shows the domain-average precipitation for this day. All of the simulations produce a peak in precipita-

Tion during the night which was not observed by the radar. As this is during the spin-up phase from the global model elds this will be ignored in our analysis. The control simulation initiates daytime convection too early on this day and 10

er-estimates the domain-average precipitation. Including the vertical fluxes from the Leonard terms improves the in tiation time and reduces the domain-average precipitation bringing it closer to the observations. This is a result of reducing the occurrence of rainrates greater than $4 \mathrm{~mm} \mathrm{hr}^{-1}$ (Fig. 10). As with the previous case, the control simulation overestimates the number of grid points with intense rainfall rates and increasing $K_{L}$ leads to a greater reduction in the number of grid points with rainfall rates exceeding $16 \mathrm{~mm} \mathrm{hr}^{-1}$, with $K_{L}=4$ and 6 tending to reduce these rainfall 


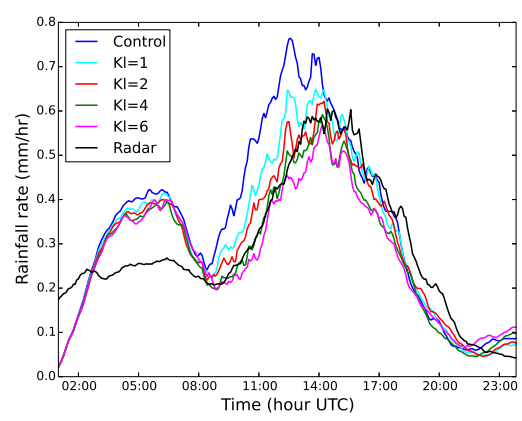

GURE 9 Domain-averaged surface rainfall rate in $\mathrm{mm} \mathrm{hr}^{-1}$ for 15 June 2016 for the control UKV simulation and the four additional simulations which include the vertical Leonard term fluxes calculated with $K_{L}=1,2,4$ and 6 spectively compared with the radar-derived surface rainfall composite.
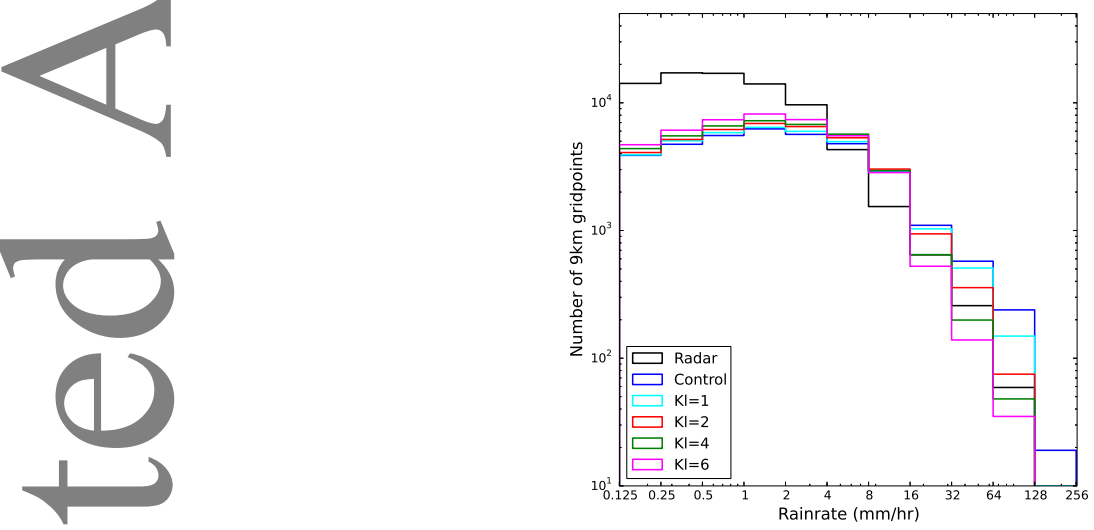

FIGURE 10 Histogram of surface rainfall rates in $\mathrm{mm} \mathrm{hr}^{-1}$ for T+9 - T+21 15 June 2016 for the control UKV simuration and the four additional simulations which include the vertical Leonard term fluxes calculated with $K_{L}=1$, 24 and 6 respectively compared with the radar-derived surface rainfall composite. All data has been regridded to o m.<smiles></smiles>
es too much compared to the radar observations. Although the lighter rainfall rates (less than $4 \mathrm{~mm} \mathrm{hr}^{-1}$ ) are underTpresented in all the simulations, in this case including the vertical Leonard terms does increase the amount of light rain compared to the control. Intuitively we would not expect the Leonard terms to impact the light rainfall rates as much as the heavy rates as they occur in regions of smaller vertical velocity where the impact of the Leonard terms is chiall.

As with the previous case, the reduction in the number of grid points with rainfall rates exceeding $4 \mathrm{~mm} \mathrm{hr}^{-1}$ seen 
when including the Leonard terms can be attributed to a reduction in the domain-mean updraught vertical velocity throughout the PBL and lower troposphere (not shown). The reduction in updraft velocity is also potentially responsible for the delay in the onset time of precipitation seen in Fig. 9. We hypothesis that decreasing the updraft velocity akes it harder for initial plumes to penetrate the CIN layer, leading to a delay in the onset time of precipitation. In this section we have shown that including the Leonard term fluxes in the UKV reduces the occurrence of rainfall es greater than $4 \mathrm{~mm} \mathrm{hr}^{-1}$ (which are overestimated by the control UKV simulation) but does not affect the rainfall $\mathrm{m}$ tes less than $4 \mathrm{~mm} \mathrm{hr}^{-1}$ (which are underrepresented in the control UKV simulation). In one case where the control tiated too early, including the Leonard terms delayed convection initiation to better match the observations but in a calse where the control UKV initiated convection at the correct time including the Leonard terms did not further delay ir tiation. In the next section the Leonard term fluxes have been trialled in the UKV for a period of one month to test if these initial conclusions still stand.

\section{2 | Bulk rainfall statistics}

T e time period chosen for assessing the impact of including the Leonard term fluxes in the UKV was 20 July - 20 A gust 2016. This was a typical summer period in the UK with a variety of frontal and convective systems. As before, ach simulation was initialised from the 00 UTC global analysis and run forward to T+24. Again histograms of surface rate and the total domain-averaged precipitation have been used to assess the impact of including the vertical L onard term fluxes. Figure 11 shows the histogram of surface rainfall rates for the 0900-2100 UTC period for 20 July to 20 August 2016. Similar to the case studies, including the Leonard term fluxes has very little impact on the sht rain (below $1 \mathrm{~mm} \mathrm{hr}^{-1}$ ) which is under-represented by the control UKV. Rainfall rates greater than $4 \mathrm{~mm} \mathrm{hr}^{-1}$ a over-predicted by the control UKV simulation. Including the Leonard term fluxes reduces the occurrence of the hflaviest rainfall rates and increasing $K_{L}$ reduces the heaviest rainfall rates further. The most extreme rainfall rates (above $64 \mathrm{~mm} \mathrm{hr}^{-1}$ ) are reduced too much with $K_{L}$ greater than 1 .

To assess the domain-averaged precipitation we have used the amplitude component of the structure, amplitude, and location (SAL; Wernli et al., 2008) rainfall verification technique. The amplitude component $A$ corresponds to the 


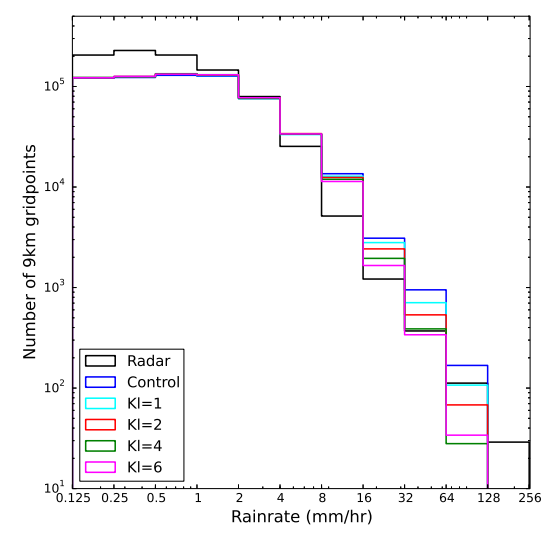

GURE 11 Histogram of surface rainfall rates in $\mathrm{mm} \mathrm{hr}^{-1}$ for $\mathrm{T}+9-\mathrm{T}+2120$ July - 20 August 2016 for the control UKV simulation and the four additional simulations which include the vertical Leonard term fluxes calculated with $=1,2,4$ and 6 respectively compared with the radar-derived surface rainfall composite. All data has been regridded to $9 \mathrm{~km}$.

normalised difference of the domain-averaged precipitation values of the modelled rain rates, $D\left(R_{\text {mod }}\right)$, and the radar served rain rates, $D\left(R_{o b s}\right)$ :

$$
A=\frac{D\left(R_{\text {mod }}\right)-D\left(R_{o b s}\right)}{0.5\left[D\left(R_{\text {mod }}\right)+D\left(R_{o b s}\right)\right]}
$$

Here the domain average precipitation is given by:

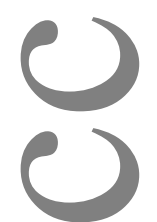

$$
D(R)=\frac{1}{N} \sum_{(i, j)=1}^{N} R_{i j}
$$

Wilere $R_{i j}$ are the grid point values. Values of $A$ range from -2 to 2 , where 0 denotes a perfect forecast and $A=1(-1)$ indicates that the model overestimates (underestimates) the precipitation by a factor of 3 . Here $D(R)$ is the domainaveraged precipitation averaged over the period 0900-2100 UTC each day. During the chosen period there were two 
days (15 and 16 August) where all the UKV simulations completely failed to simulate the observed showers. Therefore

it was decided to exclude these two days from the analysis as they gave values of $A=-2$ for all simulations which unfairly influenced the mean. Figure 12 shows the mean SAL amplitude component for each simulation averaged over 0900-2100 UTC period for 20 July to 20 August 2016 (excluding 15 and 16 August). Consistent with the case
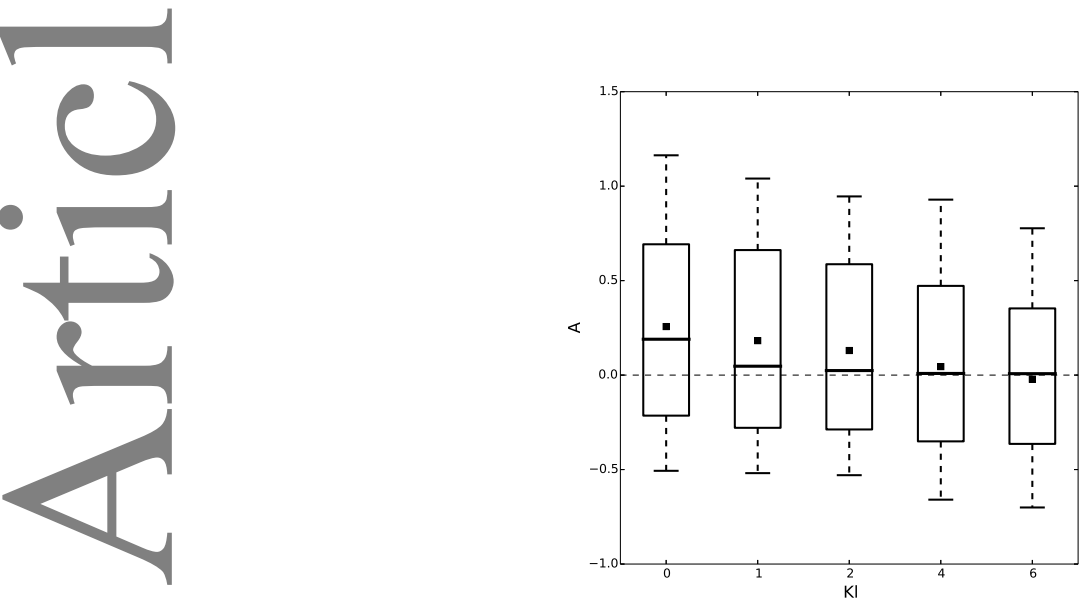

GURE 12 SAL amplitude component for the control UKV simulation and the four additional simulations which in Iude the vertical Leonard term fluxes calculated with $K_{L}=1,2,4$ and 6 for the period 0900 - 2100 UTC 20 July - 20 ugust 2016. The thick black line indicates the median, black squares indicate the mean, boxes show the interquartile range and the whiskers indicate the extreme values.

Idies, the control UKV simulation still over-estimates the domain-average precipitation when averaged over a longer P riod leading to both a positive mean value for $A$ and a positive median value. Including the Leonard terms reduces the mean ąnd median values of $A$. Increasing $K_{L}$ leads to a reduction in the mean values of $A$, with the $K_{L}=6$ simulation 1 ving a mean value closest to zero, but increasing $K_{L}$ from 1 to 6 has made little difference to the median value of This is to be expected as we have already seen that the main impact of including the Leonard term fluxes is to reduce the heaviest rainfall rates. All of the simulations show a considerable spread in values with the maximum values ing around 1 (ranging from 1.2 for the control to 0.8 for the $K_{L}=6$ simulation) meaning that the domain-average ecipitation is overestimated by approximately 3 -times compared to the radar observations. The minimum values range from -0.5 for the control to -0.7 for the $K_{L}=6$ simulation meaning that the domain-average precipitation is underestimated by a factor of 2 compared with the observations. Based on the mean and median values of $A$, the 
value of $K_{L}=6$ gives the best results. This is a slightly greater value than Verrelle et al. (2017) who found a value of $K_{L}=4$ gave the best fit of the vertical heat and moisture fluxes to their reference LES simulations.

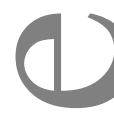

\section{I CONCLUSIONS}

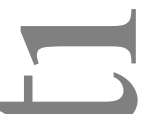

In 'this paper we have described the implementation of an extra subgrid vertical flux, referred to as "the Leonard term", ich accounts for the tilting of horizontal flux into the vertical by horizontal gradients in vertical velocity and is missing from the current subgrid mixing scheme used in the UM. We have shown that including this extra term in the Met Office UKV model reduces the domain-average precipitation by reducing the number of grid points with rainfall rates g'eater than $4 \mathrm{~mm} \mathrm{hr}^{-1}$, which are over-represented by the UKV. Increasing the magnitude of the Leonard terms furer decreases the occurrence of the heaviest rainfall rates. This is to be expected as increasing the magnitude of the onard terms via $K_{L}$, reduces the horizontal gradients thereby reducing the peak vertical velocity leading to a reduction in condensation. In one case including the Leonard terms slightly increased the occurrence of light rainfall rates (below $1 \mathrm{~mm} \mathrm{hr}^{-1}$ ), which are under-represented in the UKV. However, statistics over a month-long period showed that in general the Leonard terms do not impact the light rainfall rates. Intuitively we would not expect the Leonard $r$

$t$ rms to impact the light rainfall rates as much as the heavy rates as they occur in regions of smaller vertical velocity where the impact of the Leonard terms is small.
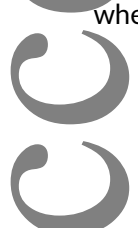

Rainfall rates from the UKV are used by the UK Flood Forecasting Centre to drive hydrological models and provide w/irnings of potential flooding events so it is important that the extreme rainfall rates are not over-predicted. It is encouraging that including the Leonard terms in the UKV can help mitigate the over-prediction of extreme rainfall rates, and no additional tuning to other parameterisation schemes in the UM, such as the Smagorinsky subgrid scheme or the microphysics scheme, was required. 


\section{ACKNOWLEDGEMENTS}

The authors would like to acknowledge Mark Weeks for maintaining the UKV research suite. Thanks also to Hilary

y eller for her assistance with the Leonard term stability analysis.

\section{SERENCES}

Beare, R. J. (2013) A length scale defining partially-resolved boundary-layer turbulence simulations. Bound-Layer Meteor., 149. 1

Best, M. J., Pryor, M., Clark, D. B., Rooney, G. G., Essery, R. L. H., Mènard, C. B., Edwards, J. M., Hendry, M. A., Porson, A., Gedney, N., Mercado, L. M., Sitch, S., Blyth, E., Boucher, O., Cox, P. M., Grimmond, C. S. B. and Harding, R. J. (2011) The Joint UK Land Environment Simulator (JULES), model description - part 1:energy and water fluxes. Geoscientific Model Development, 4, 677-699.

Boutle, I. A., Eyre, J. E. J. and Lock, A. P. (2014) Seamless stratocumulus simulation across the turbulent gray zone. Mon. Wea. Rev., 142, 1655-1668, doi: http://dx.doi.org/10.1175/MWR-D-13-00229.1.

Bryan, G. H., Wyngaard, J. C. and Fritsch, J. M. (2003) Resolution requirements for the simulation of deep convection. Mon. Wea. Rev., 131, 2394-2416.

ark, P., Roberts, N., Lean, H., Ballard, S. P. and Charlton-Perez, C. (2016) Convection-permitting models: a step-change in rainfall forecasting. Meteor. Appl., 23, 165-181.

Craig, G. C. and Dörnbrack, A. (2008) Entrainment in cumulus clouds: What resolution is cloud-resolving? J. Atmos. Sci., 65, 3978-3988.

L vies, T., Cullen, M. J. P., Malcolm, A. J., Mawson, M. H., Staniforth, A., White, A. A. and Wood, N. (2005) A new dynamical core for the Met Office's global and regional modelling of the atmosphere. Q. J. R. Meteorol. Soc., 131, 1759-1782.

assmann, A. and Herzog, H.-J. (2015) How is local material entropy production represented in a numerical model? Quarterly Journal of the Royal Meteorological Society, 141, 854-869. URL: https://rmets.onlinelibrary.wiley.com/doi/abs/ $10.1002 / q j .2404$.

Gregory, D. and Rowntree, P. (1990) A mass flux convection scheme with representation of cloud ensemble characteristics and stability dependent closure. Mon. Wea. Rev., 118, 1483-1506. 
Halliwell, C. (2007) Unified Model Documentation Paper 28: Subgrid turbulence scheme. Tech. rep., Met Office.

Hanley, K. E., Barrett, A. I. and Lean, H. W. (2016) Simulating the 20 May 2013 Moore, Oklahoma tornado with a 100-meter grid-length NWP model. Atmos. Sci. Let., 17, 453-461, doi:10.1002/asl.678.

tanley, K. E., Plant, R. S., Stein, T. H. M., Hogan, R. J., Nicol, J. C., Lean, H. W., Halliwell, C. and Clark, P. A. (2015) Mixing length controls on high resolution simulations of convective storms. Q. J. R. Meteorol. Soc., 141, 272-184, doi:10.1002/qj.2356.

rrison, D., Scovell, R. and Kitchen, M. (2009) High-resolution precipitation estimates for hydrological uses. Water Management, 162, 125.

1

rrison, D. L., Norman, K., Pierce, C. and Gaussiat, N. (2011) Radar products for hydrological applications in the UK. Proceedings of the Institution of Civil Engineers, 165, 89-103.

lloway, C. E., Woolnough, S. J. and Lister, G. M. S. (2013) The effects of explicit versus parameterized convection on the MJO in a large-domain high-resolution Tropical case study. Part I: Characterization of large-scale organization and propagation. J. Atmos. Sci., 70, 1342--1369, doi:10.1175/JAS-D-12-0227.1.

Honnert, R., Masson, V. and Couvreux, F. (2011) A diagnostic for evaluating the representation of turbulence in atmospheric models at the kilometric scale. J. Atmos. Sci., 68, 3112-3131.

Yain, J. S., Weiss, S. J., Bright, D. R., Baldwin, M. E., Levit, J. J., Carbin, G. W., Schwartz, C. S., Weisman, M. L., Droegemeier, K., Weber, D. B. and Thomas, K. W. (2008) Some practical considerations regarding horizontal resolution in the first generation of operational convection-allowing NWP. Wea. Forecasting, 23, 931-952.

Kєndon, E. J., Roberts, N. M., Senior, C. A. and Roberts, M. J. (2012) Realism of rainfall in a very high resolution regional climate IIIo del. Journal of Climate, 25, 5791--5806, DOI:10.1175/JCLI-D-11-00562.1.

an, H. W., Clark, P. A., Dixon, M., Roberts, N. M., Fitch, A., Forbes, R. and Halliwell, C. (2008) Characteristics of high-resolution versions of the Met Office Unified Model for forecasting convection over the United Kingdom. Mon. Wea. Rev., 136, 34083424, doi:10.1175/2008MWR2332.1.

onard, A. (1974) Energy cascade in large-eddy simulations of turbulent fluid flows. Advances in Geophysics, 18, $237-248$.

y, D. K. (1962) On the numerical simulation of buoyant convection. Tellus, 14, 148-172. URL: http://dx.doi .org/10.1111/ j.2153-3490.1962.tb00128.x.

Lock, A. P., Brown, A. R., Bush, M. R., Martin, G. M. and Smith, R. N. B. (2000) A new boundary layer mixing scheme. Part I: Scheme description and single-column model tests. Mon. Wea. Rev., 128, 3187-3199. 
Marshall, J., Hitschfeld, W. and Gunn, K. (1955) Advances in radar weather. vol. 2 of Advances in Geophysics, 1 - 56. Elsevier.

McBeath, K., Field, P. R. and Cotton, R. J. (2013) Using operational weather radar to assess high-resolution numerical weather prediction over the British Isles for a cold air outbreak case-study. Q. J. R. Meteorol. Soc., DOI:10.1002/qj.2123.

Mellor, G. (1973) Analytic prediction of the properties of stratified planetary surface layers. J. Atmos. Sci., 30, 1061-1069.

Moeng, C.-H. (2014) A closure for updraft-downdraft representation of subgrid-scale fluxes in cloud-resolving models. Mon. Wea. Rev., 142, 703-715.

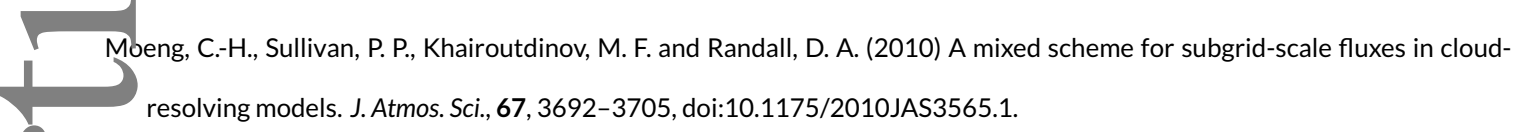

Nakanishi, M. (2001) Improvement of the mellor-yamada turbulence closure model based on large-eddy simulation data. Bound-Layer Meteor., 99, 349-378.

uyen, H., Protat, A., Zhu, H. and Whimpey, M. (2017) Sensitivity of the ACCESS forecast model statistical rainfall properties to resolution. Q. J. R. Meteorol. Soc., 143, 1967-1977, DOI: 10.1002/qj.3056.

Pé rodi, A. and Tanelli, T. (2010) Influence of turbulence parameterizations on high-resolution numerical modeling of tropical convection observed during the tc4 field campaign. J. Geophys. Res., 115.

arson, K. J., Lister, G. M. S., Birch, C. E., Allan, R. P., Hogan, R. J. and Woolnough, S. J. (2013) Modelling the diurnal cycle of tropical covection across the 'grey zone'. Q. J. R. Meteorol. Soc., DOI:10.1002/qj.2145.

Rawlins, F., Ballard, S., Bovis, K., Clayton, A., Li, D., Inverarity, G., Lorenc, A. and Payne, T. (2007) The met office global fourdimensional variational data assimilation scheme. Q. J. R. Meteorol. Soc., 133, 347-362.

chwartz, C. S., Kain, J. S., Weiss, S. J., Xue, M., Bright, D. R., Kong, F., Thomas, K. W., Levit, J. J. and Coniglio, M. C. (2009) Next-day convection-allowing WRF model guidance: A second look at 2-km versus 4-km grid spacing. Mon. Wea. Rev., 137, $3351-3372$.

hagorinsky, J. (1963) General circulation experiments with the primative equations. I: The basic experiment. Mon. Wea. Rev., 91, 99-164.

Stein, T. H. M., Hogan, R. J., Clark, P. A., Halliwell, C., Hanley, K. E., Lean, H. W., Nicol, J. and Plant, R. S. (2015) The DYMECS project: A statistical approach for the evaluation of convective storms in high-resolution NWP models. Bull. Amer. Meteorol. Soc., 96, 939-951, doi: http://dx.doi.org/10.1175/BAMS-D-13-00279.1. 
Verrelle, A., Ricard, D. and Lac, C. (2017) Evaluation and improvement of turbulence parameterization inside deep convective clouds at kilometer-scale resolution. Mon. Wea. Rev., 145, 3947-3967.

Walters, D., Brooks, M., Boutle, I., Melvin, T., Stratton, R., Vosper, S., Wells, H., Williams, K., Wood, N., Allen, T. et al. (2017) The Met Office unified model global atmosphere 6.0/6.1 and JULES global land 6.0/6.1 configurations. Geoscientific Model Development, 10, 1487-1520.

V eisman, M. L., Davis, C., Wang, W., Manning, K. W. and Klemp, J. B. (2008) Experiences with 0-36-h explicit convective forecasts with the WRF-ARW model. Wea. Forecasting, 23, 407-437.

V'ernli, H., Paulat, M., Hagen, M. and Frei, C. (2008) SAL-A novel quality measure for the verification of quantitative precipitation forecasts. Mon. Wea. Rev., 136, 4470-4487, doi:10.1175/2008MWR2415.1.

Wilson, D. R. and Ballard, S. P. (1999) A microphysically based precipitation scheme for the UK Meteorological Office Unified Model. Q. J. R. Meteorol. Soc., 125, 1607-1636.

pod, N., Staniforth, A., White, A., Allen, T., Diamantakis, M., Gross, M., Melvin, T., Smith, C., Vosper, S., Zerroukat, M. et al. (2014) An inherently mass-conserving semi-implicit semi-lagrangian discretization of the deep-atmosphere global nonhydrostatic equations. Q. J. R. Meteorol. Soc., 140, 1505-1520.

Wyngaard, J. C. (2004) Toward numerical modelling in the "terra incognita". J. Atmos. Sci., 61, 1816-1826.

(2010) Turbulence in the Atmosphere. Cambridge University Press. 1

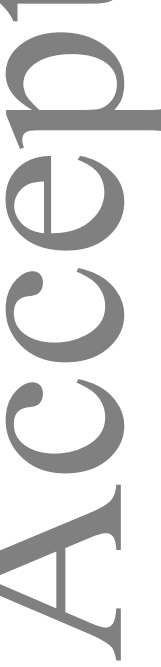

